\title{
história, PREssácios MEMORÁVEIS E A MORTE DO IMPERADOR JULIANO NA OBRA DE AMIANO MARCELINO (390-392 D.C.)
}

History, Memorable Omens and the Death of the Emperor Julian in Ammianus Marcellinus' Work (390-392 AD)

\section{RESUMO}

Neste artigo, temos a intenção de analisar os livros XXIII a XXV da obra Res Gestae de Amiano Marcelino, a respeito dos momentos cruciais da guerra contra os persas e da morte de Juliano no meio de uma batalha contra esses adversários. Esse estilo faz parte do gênero romano do discurso bellum, ilustrado por Salústio (86-35 a.C.) e Júlio César (10044 a.C.), assim como o estilo da biografia imperial cujo desenvolvimento ocorreu até a Antiguidade Tardia. Pretendemos interpretar episódios que ocorreram antes e durante a morte do Imperador Juliano na visão desse autor militar. O texto será desenvolvido tendo como base a metodologia da História das Emoções. Dessa forma, serão ressaltados sentimentos como o medo e a coragem que se mesclam no decorrer da narrativa.

Palavras-chave: História, Presságios, Morte, Juliano.
Margarida Maria de

\section{CARVALHO}

(D) margarida.carvalho@unesp.br

Universidade Estadual

Paulista,

Franca, SP, Brasil

\begin{abstract}
In this article, l'd like to analyze the books XXIII-XXV of Ammianus Marcellinus' Res Gestae, about the crucial moments of the war between Romans and Persians. At the same time, I intend to understand Julian's death in the battle against these enemies. This style is a part of the bellum gender, illustrated by Sallustius (86-35 BC) and lulius Caesar (100-44 BC). It's also included in the imperial biography style, whose development occurred until the Late Antiquity. l'll interpret the episodes that happened before and after the death of the Emperor Julian in the vision of this military writer. This text will be based in the methodology of the History of Emotions. In this way, I want to stand out sentiments like fear and courage that blend together in the course of the narrative.
\end{abstract}

Keywords: History, Omens, Death, Julian. 


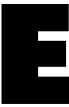
m 299 d.C. ${ }^{1}$, ainda no período da Tetrarquia, mais especificamente no governo de Diocleciano (284-305), houve um tratado de paz do Império Romano com os persas. Foi o chamado Tratado de Paz de Nísibis, onde a Pérsia perdeu territórios como os da Armênia e da Mesopotâmia. A partir do Imperador Constantino (306-337), alguns povos que eram inimigos dos persas se tornaram seus aliados, fato esse que se transformou em um estorvo para os romanos. Os persas não precisaram mais se preocupar com outras fronteiras e seu alvo passou a ser o Império Romano. Dessa forma, a partir de Constâncio II (337-361), guerras sucessivas foram realizadas entre romanos e persas (SEAGER, 1997, p. 255-256). Após o imperador ariano, coube a Juliano (361-363) a escolha de continuar com essa árdua tarefa, preparando-se militarmente para o confronto com a Pérsia, de março a novembro de 362, na cidade de Antioquia. Sua estada nessa cidade, com status de província, foi bastante tumultuada, como indicam as suas cartas e o seu discurso Misopogon², ambos escritos em Antioquia.

Neste artigo, temos a intenção de analisar os livros XXIII a XXV da obra Res Gestae de Amiano Marcelino, a respeito dos momentos cruciais da guerra contra os persas e da morte de Juliano no meio de uma batalha contra esses adversários. Esse estilo faz parte do gênero romano do discurso bellum, ilustrado por Salústio (86-35 a.C.) e Júlio César (100-44 a.C.), assim como o estilo da biografia imperial cujo profícuo desenvolvimento ocorreu até a Antiguidade Tardia. Logo, são dois princípios bem equilibrados na trilogia aminiana.

O livro XXIII trata dos preparativos para a guerra enquanto que o livro XXIV discorre a respeito dos dramas e ofensivas, inicialmente vitoriosas, porém as batalhas se tornam cada vez mais difíceis à medida que a resistência persa aumenta. Refere-se também ao atropelamento das ordens e contra ordens do Imperador em Ctesifonte. ${ }^{3}$ Naquele momento, houve um incêndio na rota de colisão que gerou um fracasso na tentativa de avançar em direção a outras regiões da Pérsia. Amiano relata igualmente o desafio realizado em forma de sacrifícios aos deuses e a ordem dos retrocessos das batalhas. No tocante ao livro XXV, o historiador antioquiano comenta as agonias do exército romano, traduzidas em forma de fome e exaustão. Finalmente, ele disserta sobre a morte de Juliano, perfurado nas costelas por uma lança proveniente do inimigo. Tal livro pode ser interpretado como um misto de críticas sutis e muitos elogios da parte do autor. (FONTAINE, 2002, p. 8-10).

Apesar de ser um tema muito explorado pela historiografia acerca de Juliano em Amiano Marcelino, tentaremos concretizar uma nova abordagem sobre o assunto. Em primeiro lugar, além de tecermos algumas considerações sobre a contextualização da obra, será apresentada uma abordagem inédita da concepção de História para a obra do autor antioquiano, baseada não somente em suas memórias, mas também nas emoções por ele transmitidas. Citaremos o medo sentido pelo autor e pelo personagem dos presságios comunicados aos dois. Em segundo lugar, analisaremos a morte de Juliano relatada por Amiano, sugerindo uma interpretação original relativa a esse acontecimento. Por exemplo, há várias descrições no que tange ao óbito do Imperador filósofo, porém nenhuma delas considerou seus sentimentos contraditórios na preparação da guerra e durante as batalhas contra os inimigos persas. 


\section{Particularidades da vida e da obra de Amiano Marcelino}

De acordo com Edward Arthur Thompson (1947) e Timothy Barnes (1998), Amiano Marcelino teria nascido entre 325 e 330, na cidade de Antioquia, proveniente de uma família não cristã e com certo grau de nobreza, da ordem dos Decuriões. Apesar de pertencer a uma família abastada, assim como o seu pai, seguiu a carreira militar. Ingressou no exército em 350 e foi protectores domestici, ou seja, o responsável pelo abastecimento militar e pela execução de uma série de estratégias militares. Portanto, fez parte de um regimento de alto nível bélico. É interessante relembrarmos que Diocleciano e Constâncio Il possuíam esse cargo quando se tornaram imperadores.

O autor militar participou ativamente das expedições contra os persas nos governos de Constâncio II e de Juliano. Assim sendo, foi testemunha ocular dos episódios de combate travados entre os romanos e os persas. Após a morte de Juliano, em junho de 363 , Amiano se afastou da vida militar, retornando à cena política-cultural em 378, no início do governo de Teodósio I (378-395), residindo em Antioquia. Segundo John Curran (1998), aquele Imperador ascendeu a tal posto, uma vez que Graciano (367-375) necessitou de alguém com uma maior experiência militar para combater os germanos nas fronteiras ocidentais. Logo, em dezenove de janeiro de 379, coroou Flávio Teodósio como imperador, um general de habilidades extraordinárias que vivia distanciado do cenário político-militar desde a dramática execução de seu pai, em 374. Uma forte particularidade do governo de Teodósio I foi a crescente admissão de estrangeiros no exército romano em número sem precedentes. Mesmo os desertores dos exércitos germânicos além do Danúbio foram admitidos.

Com o avanço dos godos no território romano, um acordo entre eles e Teodósio I foi considerado uma séria derrota para os romanos. O Imperador abrigou o rei Atanarico, que tinha fugido de conflitos internos de seu reino para a corte teodosiana, em Constantinopla, no mês de janeiro de 381. Ainda seguindo o raciocínio de Curran, Saturnino, magister militum de Teodósio I, assinou um tratado com o restante dos godos, em três de outubro de 382. Tal acordo permitiu o assentamento de um grande número de estrangeiros no território romano, a saber: nas regiões do Danúbio, da Trácia e da Macedônia. Isto posto, os germânicos viveram como povos distintos dentro das fronteiras do Império Romano e serviram como aliados - foederati - quando foram recrutados para as guerras do período (CURRAN, 1998). Ao observar as tropas militares de Teodósio I, Amiano sentiu inspiração para descrever a respeito do exército de Juliano. Ademais, no período teodosiano, houve a realização de tratados com os persas, prejudiciais aos romanos. No tocante à religião, foi feita a oficialização do cristianismo ortodoxo, o que permitiu aos cristãos da época a elaboração de críticas severas à política religiosa de Juliano. Como sabemos, ele ficou reconhecido na História como o Apóstata, termo instituído pelos cristãos e que possui um sentido pejorativo, o qual não deve ser perpetuado. Ao mesmo tempo, muitos súditos romanos criticaram a política militar de Teodósio I, relembrando as ações ofensivas de Juliano contra os persas.

Conforme Barnes (1998, p. 1), Amiano Marcelino deixou o exército em 378 e passou a se recolher em Antioquia, sua cidade natal. Em uma das últimas fases de 
sua estada no exército romano, atravessou a Península Balcânica, assistindo as lutas entre godos e romanos. Como já mencionamos anteriormente, Marcelino parece não ter apreciado o contrato realizado entre Teodósio I e os godos. De mais a mais, com a morte de Sapor II, em 379, e com as migrações dos hunos para o Império Persa e Romano, houve a realização de acordos entre Teodósio I e os persas. Tudo indica que tais episódios não foram do agrado de Amiano Marcelino, pois fez questão de marcar em sua obra o quanto houve na história do Império Romano imperadores destemidos, como Constâncio Il e, sobretudo, Juliano. Ambos lutaram incessantemente contra os persas. Em 392, era o momento adequado de lembrar os feitos de Juliano através da leitura pública de sua obra em Roma, antiga capital do Império.

Foi nessa contextualização que Amiano Marcelino escreveu a sua obra, especialmente a trilogia acima mencionada, redigida aproximadamente no arco temporal de 390 a 392. Como veremos mais adiante, pode-se fazer uma conexão dos relatos do autor com sua realidade presente. Amiano não deixou de fazer críticas, mesmo que indiretamente, às práticas governamentais de Teodósio I, acima de tudo, no campo militar. Por conseguinte, devemos averiguar não somente o conteúdo e a forma da Res Gestae, mas também os diferentes aspectos que a representação histórica assume na concepção de seu autor. As seções que se referem aos confrontos bélicos não devem ser tratadas com indiferença, porque transmitem, ao mesmo tempo, os pensamentos políticos de Marcelino. Dentro de seus pensamentos político-religiosos, notamos que Amiano possuía fé em uma divindade suprema, incluindo a crença em divindades menores, todas neoplatonicamente concebidas (GRATTAROLA, 1981).

Em relação ao conteúdo da obra, Olivier Devillers (2002, p. 61) comentou que, do ponto de vista historiográfico, Amiano faz coexistir dois modos de informações: a leitura de autores anteriores e a experiência pessoal. Por exemplo, utiliza Heródoto (485-425 a.C.) como modelo de interação entre uma tradição literária e sua contemporaneidade, a fim de dar uma ideia de continuidade e de uma longa duração da cultura persa. Além disso, é seguro, em nossa opinião, que o historiador se inspirou nos relatos bélicos de Políbio (220-146 a.C.), pois tal autor que retratou as Guerras Púnicas também viveu dois episódios daquela guerra em seu tempo presente. Para Jacques Fontaine (2002, p. 23-24), o autor antioquiano, ao escrever a sua obra, inspirou-se em Gregório de Nazianzo (329-390), Libânio (314-394), João Crisóstomo (349-407), Eutrópio (final do séc. IV), Eunápio (349-420) e Festo (final do séc. IV), escritores a ele coetâneos.

Existem autores, como Thompson (1947, p. 17), que afirmaram a influência da obra de Tácito (56-120) sobre Amiano Marcelino. Para esse autor da metade do século passado, Amiano teria continuado as Histórias e os Anais de Tácito. Pois é sabido que a obra do antioquiano era composta por trinta e um livros, sendo que os quatorze primeiros foram perdidos. Justamente no primeiro livro, Amiano teria iniciado a sua narrativa compondo a vida de Nerva, ponto esse em que Tácito parou em suas Histórias. O tradutor dos livros de Amiano na versão britânica, John Carew Rolfe (1950, p. 27) ponderou que Amiano teria prosseguido com o projeto de Tácito, imitando-o no máximo que pode. Mas, através da crítica de Leland Edward Wilshire (1973, p.222) Amiano não seguiu Tácito de forma consciente e deve ser visto no 
contexto da historiografia do século IV, sendo interpretado, também, como aquele que se conectou com os escritos posteriores a Suetônio (69-141).

Concordamos com Wilshire (Ibid.) quando afirmou que Amiano Marcelino deve ser colocado em um alto patamar de originalidade, porque ultrapassou os limites dessa tradição. Não há nenhuma menção a Tácito em sua obra, tão pouco documentos que evidenciem qualquer relação entre os dois autores. De acordo com Barnes (1998, p. 43-45), Amiano não se utilizou de nenhuma estrutura analítica e formal como Tácito, que teria programado uma estrutura de redação onde os acontecimentos por ele narrados ocorressem de forma relativamente precisa. No caso de Amiano, a título de exemplo, temos a menção aos consulares sem uma intenção objetiva. É claro que Barnes declarou isso em uma época em que se acreditava em fatos casuais na História. Somos da opinião de que nada ocorre por acaso, mas é perceptível que a programação de escrita de Tácito era muito diferente da de Amiano Marcelino. Ele explora a fórmula consular de diversas maneiras, mas sempre para melhorar sua representação favorável a Juliano.

Nos livros aqui analisados, o autor militar se prende a narrativa de intercorrências da guerra de Juliano versus persas, portanto, seu limite temporal é mais curto do que o de Tácito. Percebe-se, claramente, nesse sentido, a influência da forma de História de Tucídides (460-400 a.C.) na obra do antioquiano, uma história de curta duração pautada em seu testemunho ocular e em suas memórias. A escritora Agnese Bargagna (2015, p. 335-336) corroborou essa tese ao afirmar que é difícil ressaltar que Amiano tenha visto Tácito como um modelo, apesar de possuírem semelhanças textuais. A diferença entre eles é que o escritor bélico foi muito alusivo e sua predileção pela contaminatio foi clara. A contaminatio é um procedimento que o levou a inserir em sua obra referências de textos diversos ou excertos diferentes de um mesmo texto. Assim, acrescentamos que ele também se inspirou na Coleção Médica (ORIBASE, Collection Médicale) dedicada a Juliano, de autoria de seu médico particular, Oribásio de Pérgamo (320-400). É importante comentar que tal médico era amigo íntimo de Juliano e que o acompanhou em suas tarefas militares, desde sua época de César (355-361).

Apesar de todas as influências supracitadas, é importante ressaltarmos que Amiano possui uma grande originalidade na escrita de seu texto. Nos livros XXIII e XXIV, ele se preocupa em relatar os momentos da guerra entre Juliano e os persas. Já no livro $\mathrm{XXV}$, concomitantemente ao relato do desfecho da mesma, finalizada pela morte de Juliano, Marcelino não deixa de tecer inúmeros comentários elogiosos ao princeps, realizando uma espécie de panegírico.

Estávamos nos preparando para servir o Imperador, não com as iguarias que um princeps estava acostumado a comer, mas uma pequena porção de polenta, sob a tenda na qual ele acampava. Uma comida que nem mesmo os soldados tinham coragem de comer (AMMIEN MARCELLIN, Histoires, XXV, 2, 2). 
Nesse trecho acima, Juliano compartilha com seus soldados qualquer tipo de dificuldades, inclusive aquelas relacionadas à alimentação. Ainda é visível que o antioquiano destaca a simplicidade do general governante ao se alimentar. De fato, o Imperador se alimentava de maneira muito frugal, visto que era neoplatônico e não consumia carnes, como podemos averiguar em algumas passagens de seu discurso Misopogon e nas dietas prescritas para ele por Oribásio. Ao mesmo tempo em que o autor militar heroifica Juliano, ele faz críticas explícitas a algumas decisões do Imperador. Como exemplo, citamos a passagem abaixo, referenciando um erro estratégico de Juliano ao queimar sua frota abastecida de provisões:

Esse incidente aniquilou a nossa frota quando não era necessário. Juliano, confiante nas forças concentradas de seu exército, invadiu o território inimigo com superioridade numérica, uma vez que suas tropas não estavam mais ocupadas com tarefas de abastecimento, graças à abundância de alimentos do território persa. Ao captar essa intenção, o inimigo incendiou as plantações, causando a fome e o impedimento do avanço das tropas romanas (AMMIEN MARCELLIN, Histoires, XXIV, 7, 6-7).

Nas palavras de David Rohrbacher (2007), o público alvo da Res Gestae foi os funcionários imperiais e os militares veteranos, que não se encontravam mais na ativa, e o tradicionalismo político e religioso de Marcelino foi um novo ingrediente historiográfico à época. Em particular, ele incorporou elementos de tratados científicos, biografias, oratórias, sátiras e até o romance em seu trabalho, traços esses que facilitaram a recepção de sua obra. A nosso ver, seus escritos foram vistos como uma crítica a muitos funcionários aristocráticos que apoiavam Teodósio I em suas ações administrativas e bélicas. Como um amante da tradição dos valores romanos, para o autor bélico, Juliano foi um exemplo da boa moral dos antigos e da familiaridade da literatura clássica.

Ainda para Rohrbacher (Ibid.), o aprendizado julgado superior foi equivalente a uma moral que ultrapassava e acendia, na visão de Marcelino, os limites da moral de sua época. Como muitas elites meritocráticas em ascensão, os membros da burocracia tardia romana defendiam a educação em torno da linhagem sanguínea. Personagens históricos, como Amiano Marcelino, apresentavam-se como herdeiros de um passado clássico e, dessa maneira, estavam dispostos a ignorar as diferenças religiosas e regionais com o intuito de promover seus interesses de grupo social. Roma, cidade considerada eterna e sempre muito importante para o Império Romano como um todo, foi considerada um local ideal para a leitura da Res Gestae de Amiano Marcelino, redigida em latim como uma forma de ovacionar a tradição. Percebe-se, em Bargagna (2015), que o autor militar, para além de usar o latim nos termos que citamos, o utilizava como uma ferramenta expressiva, do mesmo modo que Tito Lívio (59 a.C.-17 d.C.) e Tácito. Especialmente no final do século IV, o latim se tornara um símbolo de sucesso e distinção social, por isso, a escolha de escrever nessa língua foi natural para Marcelino. No entanto, isso não significa que ele deixava de seguir a tradição grega, como a de Tucídides e Dião Cássio (155-235). Consequentemente, 
devemos considerá-lo como uma síntese das culturas latina e grega, não existindo uma tensão entre elas.

Em nossa opinião, a Pérsia nunca foi descrita com tantos detalhes antes da obra Res Gestae. Devillers (2002) atribui ao autor militar um sentimento de continuidade temporal, isto é, o escritor inicia um histórico detalhado sobre a Pérsia a partir de Ciro (559-530 a.C.), conhecido como Ciro, o Grande, até os adversários de Juliano. No livro XXIII, é visível o quanto Amiano descreve a geografia, as etnias e as relações comerciais estabelecidas pela Pérsia com outras regiões. Há uma clara intenção do autor em nos passar uma ideia aumentada das características do inimigo. Além das digressões fazerem parte da historiografia do mundo clássico e tardio, elas se apresentam na obra de forma amplificada para nos dar a ideia do quanto o inimigo era poderoso. Juliano e suas tropas, então, estariam combatendo forças adversárias cujo embate poderia trazer tanto a glória quanto a derrota. Foi um recurso igualmente utilizado por Políbio quando ele descreveu as Guerras Púnicas. Com todos esses ingredientes, Amiano procura elucidar o valor da campanha de Juliano.

Nesse mesmo livro, percebe-se a insistência de Marcelino em transmitir a extensão espacial e temporal do inimigo. Outras características são acentuadas em seu testemunho como, por exemplo, o caráter compósito heterogêneo do povo persa:

\begin{abstract}
Nesses povos heterogêneos e múltiplos, até a diversidade dos homens é tão grande quanto a dos lugares. Mas - para não nos limitarmos a uma descrição geral de suas características físicas, a exemplo de nossos predecessores - eles são quase todos esbeltos, a pele ligeiramente morena ou levemente acinzentada, os olhos oblíquos como cabras, as sobrancelhas curvadas e cerradas ao mesmo tempo, a barba muito bonita, os cabelos longos e volumosos. Todos, indistintamente, carregam a espada ao lado do corpo, mesmo nos dias festivos; segundo Tucídides, cujo testemunho é incontestável, os atenienses foram os primeiros a rejeitar esse costume, que também era de seus antecessores helênicos (AMMIEN MARCELIN, Histoires, XXIII, $6,75)$.
\end{abstract}

Nota-se, na citação acima, o engrandecimento proposital feito por Amiano do povo persa. Trata-se de uma tática discursiva com o fito de mostrar a bravura e a coragem de Juliano ao enfrentar um inimigo repleto de qualidades. Observamos de maneira semelhante à ideia do conteúdo explanado acima, o trecho abaixo:

Os habitantes de todo esse território são silvícolas e combatentes, eles amam tanto uma simples luta quanto a guerra, sentindo-se felizes mesmo em ocasião da morte nas batalhas. Quando eles morrem por outros motivos, sem ser na guerra, são insultados, sendo chamados de degenerados e covardes (Ibid., XXIII, 6, 44).

Nesta passagem, o autor militar se refere aos partos que, naquele momento, guerreavam ao lado dos persas contra os romanos. Os excertos supracitados clareiam os motes amplificadores de Amiano. Então, a tarefa de Juliano teria sido árdua, 
exigindo esforços e treinamentos constantes da parte do Imperador. O antioquiano, ao destacar o perigo iminente que ameaçava Juliano e suas tropas, faz uma miscelânea do desconhecido com o maravilhoso. Isso significa que, nos livros XXIII a XXV, Marcelino concretiza um esforço para igualar os persas e partos aos romanos. Em vista disso, fazem-se presentes, assim como as ampliações, as minimizações de alguns fatos, o uso de expressões negativas e as omissões.

O historiador elenca vários predicados a Juliano, dentre eles, sua castidade, sua já referida forma de alimentação frugal e sua dedicação aos assuntos administrativos e filosóficos:

Se as lamparinas pudessem falar, expressariam tudo que assistiam, pois ficavam acesas durante toda a noite. Juliano só parava de trabalhar quando as suas exigências físicas se faziam presentes. (Ibid., XXV, 4, 6).

Além do autor bélico, Joseph Bidez (2012) também falou sobre a castidade do Imperador, após a morte de sua esposa Helena. Devemos levar em consideração que a sua abstinência sexual estava intrinsicamente ligada aos seus aprendizados neoplatônicos e aos fundamentos dos Mistérios de Mitra:

\begin{abstract}
Esse deus exigiu de seus seguidores, acima de tudo, a coragem para permanecerem todos os dias no posto atribuído a eles; então, para si mesmos, eles tinham que praticar a castidade e a pureza, a resistência à sensualidade sendo uma das formas de combate que o mitraísmo teve que apoiar contra o princípio do mal; enfim, para com os outros homens, eles tinham que mostrar sinceridade, lealdade, justiça e principalmente humanidade ou filantropia (BIDEZ, 2012, p. 162).
\end{abstract}

Portanto, Amiano Marcelino concretiza, de forma equilibrada, críticas e elogios a Juliano. Segundo, Daniël den Hengst (2010, p. 309), a composição da psicologia de Juliano é única, porque as boas qualidades do Imperador são classificadas de acordo com as quatro virtudes cardeais na seguinte ordem: temperança, prudência, justiça e fortuna. Quanto à virtus, que significava para Amiano "virtude em geral”, no caso de Juliano, o antioquiano substituiu o termo por liberalitas, indicando uma qualidade da qual Juliano muito se orgulhava: a philantrōpía. ${ }^{4}$

É visível a tentativa de Amiano de contrabalancear as qualidades e defeitos do princeps. Podemos observar, na passagem abaixo, a crítica ao caráter inconstante e supersticioso de Juliano, paralelamente ao esforço dele próprio para se controlar.

Uma vez expostas as virtudes que conhecemos, dispomo-nos, agora, a mostrar suas faltas, ainda que sejam poucas. Era de caráter inconstante, mas se corrigia com um autocontrole severo, já que tentava se repreender no limite do que era justo. Era muito falante, raramente ficava calado. Aficionado na crença de presságios era tão supersticioso quanto Adriano, pois Juliano levava muito a sério sua religião helênica. Imolava inúmeras 
vítimas bovinas sem nenhum escrúpulo, se tivesse voltado da guerra como vencedor, não haveria bois suficientes para nenhum sacrifício. Nesse ponto, lembrava muito o Imperador Marco Aurélio. (AMMIEN MARCELLIN, Histoires, XXV, 4, 16-17).

A seguir, desenvolveremos um novo conceito de História em Amiano Marcelino, baseado na análise dos sentimentos e emoções de seu principal personagem histórico, Juliano. Trataremos, também, de interpretar a visão do autor antioquiano sobre a morte do princeps.

\section{Concepção histórica, sentimentos e presságios}

Para além dessas considerações, é fundamental ressaltarmos que Amiano Marcelino, afora o fato de escrever uma obra repleta de mensagens críticas ao seu tempo, apresenta uma dupla face interpretativa que merece ser investigada. Sua redação oscila entre uma ansiedade repleta de presságios e uma esperança de um exército sabiamente comandado. Aqui, nos referimos aos seus relatos sobre Juliano ao enfrentar os persas: o Imperador foi supersticioso e corajoso ao mesmo tempo, nas palavras do referido escritor. Assim, no pensamento de Fontaine (2002, p. 17), foi importante para Marcelino se lembrar do que foi planejado e do que realmente aconteceu. Dessa maneira, a memória dos eventos foi fracionada. Logo, as memórias do autor e as informações de seus diários podem ou não ser correspondentes à realidade, portanto, há uma mescla de medo e louvor na descrição de seu herói. Não foi à toa que o historiador dedicou dez livros à vida do Imperador Juliano.

A Res Gestae, de Amiano Marcelino, é preenchida por uma memória seletiva, isto é, fatos que são selecionados pelo autor para dar vida ao seu testemunho. É certo que seu conceito de História é baseado na tradição oral e no testemunho ocular. Todavia, ressaltamos que tal concepção compreende elementos emocionais e sentimentais. Levando em consideração a proposta de Barbara H. Rosenwein (2011) para o estudo de comunidades emocionais, observamos que o autor antioquiano representa uma comunidade de militares e de funcionários preocupados com a passividade de certos imperadores, como Teodósio I. Juliano representava o último suspiro de um general imperador que teve coragem suficiente para enfrentar o inimigo persa. Porém, dotado de um sentimento de medo, perdeu-se dentro de suas superstições. Ao descrever cenas da guerra e ao mostrar as superstições de Juliano, as crenças, atitudes e valores de Amiano influenciam na construção da imagem do comportamento moral do Imperador neoplatônico.

Existem em Marcelino sentimentos dele mesmo que são projetados na figura de Juliano. Na opinião de Barbara Sidwell (2008), essa projeção é um mecanismo de defesa em que o indivíduo projeta seus próprios sentimentos desagradáveis em outra pessoa. Contudo, ao longo de nossos estudos sobre o Imperador Juliano, analisando suas próprias documentações e de autores a ele contemporâneos, percebemos que em suas epístolas e discursos filosóficos, o próprio transmite diversos sentimentos ligados à superstição. Por esse motivo, cremos que Amiano não faz apenas uma transferência de sentimentos, mas que Juliano realmente era supersticioso. 
Antes de iniciar a guerra contra os persas, o Imperador constantinopolitano consultou um oráculo cuja voz previu a sua morte. Esse fato influenciou profundamente nas atitudes de Juliano, causando-Ihe muitas inquietações. Lembremos aqui que tal personagem já estava vindo de uma sequência de acontecimentos perturbadores, ocorridos em Antioquia. Lá, ele teve muitos problemas com os decuriões e outras camadas da sociedade antioquiana. ${ }^{5}$ Eunápio (347-414), sofista e biógrafo, relata-nos em uma passagem de sua obra, Vida dos sofistas, o que Proerésio (276-368) ${ }^{6}$ comentou, indiretamente, sobre o oráculo que teria previsto a morte de Juliano.

No governo do Imperador Juliano, Proerésio foi excluído do campo da educação porque tinha a reputação de ser cristão; ao observar que o hierofante estava acessível a ele, fraudulou a regra que o impedia de consultá-lo. Pois o Imperador estava beneficiando os helenos ao aliviá-los de impostos opressivos. Então, Proerésio questionou ao Deus Supremo se essa benevolência seria permanente. $E$ quando Ihe foi declarado que não, Proerésio aprendeu o que o futuro traria e continuou com suas tarefas (EUNAPIUS, The lives of the Sophists, 493).

Proerésio foi vítima da lei escolar de Juliano, referenciada no Código Teodosiano (CTh. XIII, 3, 5) e em sua carta de número 61c, de acordo com a classificação de BidezCumont. Essa lei, promulgada por volta de agosto de 362, proibia os professores cristãos de lecionarem nas escolas. O extrato referido acima menciona a consulta de Proerésio a um oráculo, o qual previu a súbita morte de Juliano. O conteúdo dessa profecia foi referenciado pelo historiador Bidez:

Quando você subjugar os persas sob seu cetro, E até a Selêucia persegui-los com a sua espada, Você cavalgará em direção ao Olimpo, numa carruagem de fogo, Que tremerá nos turbilhões da região das tempestades.

Livre do sofrimento doloroso dos membros mortais, Você chegará à luz etérea da corte real de seu pai, Onde você vagou no passado, antes de habitar o corpo de um homem.

(BIDEZ, 2012, p. 325).

É clara a alusão à morte do Imperador. Juliano tinha conhecimento desse oráculo e já partiu para a guerra sabendo que ia morrer. Seu jeito supersticioso de ser não deixou de acreditar em todas as palavras da profecia do oráculo. Tal fato pode ser atrelado às análises das passagens sobre o conflito bélico inseridas na Res Gestae. Observa-se que diante da insatisfação das tropas com os baixos recursos recebidos, no trajeto para a Pérsia, Juliano insinua que sua morte está próxima. Ele declara que não tem medo do confronto, mesmo sozinho, uma vez que não pode fugir de seus deveres como imperador. São sinais evidenciados por ele e, paralelamente, Amiano Marcelino ressalta sua coragem como um militar, o que é demonstrado pelo discurso de Juliano aos seus soldados, transmitido na Res Gestae: 
Antigamente dotada de imensos recursos, a República Romana, acredite bem, está na última miséria por culpa daqueles que, para se enriquecerem ainda mais, ensinaram os príncipes a comprar constantemente dos bárbaros a paz pelo preço do ouro. O tesouro público é pilhado, as cidades arruinadas, as províncias devastadas. De minha parte, não tenho recursos nem relações familiares, apesar de minha nobre origem, mas apenas um coração livre de todo medo: um imperador que coloca todos os bens no cultivo da alma não terá vergonha em admitir uma pobreza honrosa. Mas se você se rebelar, voltando à ignomínia dos acontecimentos passados, bem, continue! Morrerei sozinho, de pé, no final de uma carreira cheia de obrigações pesadas, determinado a desprezar um sopro de vida de maneira que uma febre desagradável será o suficiente para me afastar (AMMIEN MARCELLIN, Histoires, XXIII, 3, 4-7).

Voltando a mencionar os presságios, Juliano ignora um aviso do prefeito da Gália, Salústio (séc. IV), um amigo neoplatônico, sobre sua morte. Segundo Amiano Marcelino, o Imperador recebeu uma carta de Salústio, pedindo para que Juliano não invadisse a Pérsia, porque sua morte seria certa:

Mas enquanto Juliano estava em Circésio, aguardando o tempo necessário para atravessar o rio com seu exército e suas provisões, ele recebeu uma carta pessimista de Salústio, que the implorou que detivesse sua campanha contra os persas. Segundo esse prefeito da Gália, a morte de Juliano seria inevitável, porque as orações do Imperador ainda não haviam apaziguado os deuses. Desdenhando, no entanto, um conselheiro tão sábio, ele continuou sua marcha adiante (Ibid., XXIII, 5, 4-5).

Vemos duas suposições a respeito do que foi escrito acima: em primeiro lugar, como já mencionamos anteriormente, Juliano, no papel de general, jamais poderia abandonar as suas tropas e, em segundo lugar, supersticioso como era, sabia que sua morte seria inevitável. Traçando o caminho do exército entre Antioquia, a travessia do Eufrates e a sua chegada à Mesopotâmia, o autor bélico descreveu alguns maus presságios vividos em tal trajeto. Antes mesmo de chegar à Pérsia, Juliano teve alguns acidentes imprevistos, que muito o impressionaram:

Partindo na manhã do dia 5 de março, ele chegou a Hierápolis pelos caminhos habituais. Quando atravessou os portões desta vasta cidade, um pórtico de repente desabou ali à sua esquerda e cinquenta soldados, que estavam alojados abaixo, foram esmagados sob uma enorme massa de vigas e telhas, sem contar o grande número de feridos. De lá, tendo concentrado todas as suas forças, ele rapidamente se moveu em direção à Mesopotâmia, a fim de aproveitar para surpreender o inimigo, mas precisou improvisar uma ação estratégica na Assíria. Depois 
de atravessar o Eufrates com os barcos alinhados, junto com o seu exército e os auxiliares citas, chegou a Batné, município de Osrhoene, onde um presságio sinistro o aguardava. Numerosos soldados próximos de um imenso amontoado de palha, como são organizados nessas regiões, estavam colhendo forragens, quando tal monte desmoronou em cima deles, esmagando mais cinquenta homens (Ibid., XXIII, 2, 6-8).

Mais uma vez, notamos uma amplificação realizada por Amiano Marcelino, o que não invalida a ocorrência desses acidentes em menor escala. O mais importante é como esses eventos foram interpretados pelo autor antioquiano e pelo próprio Juliano: os presságios foram manifestos em todos os aspectos possíveis, não só apontando a rota das batalhas, mas a rota para o óbito do Imperador. Podemos verificar no mapa abaixo, o percurso efetuado pela expedição militar, de Constantinopla até Batné.

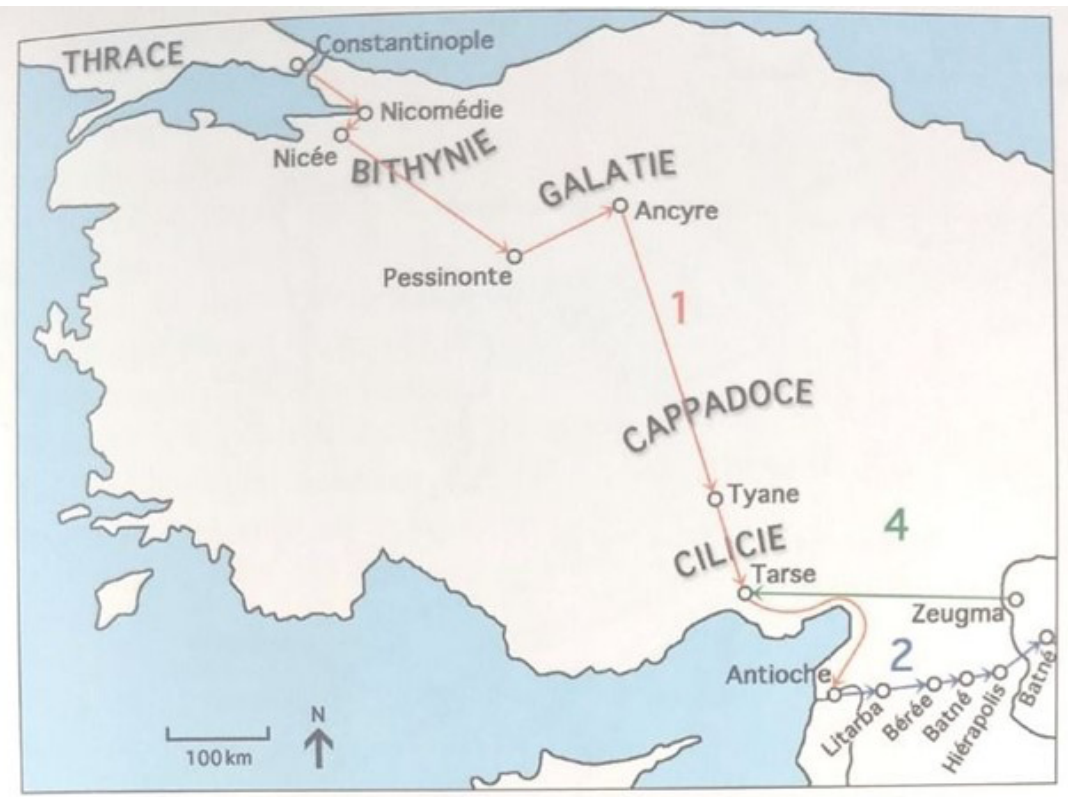

Figura 1 - Itinerário de Juliano

Fonte: WOLFF, Catherine. La campagne de Julien en Perse, 363 apr. J -C. Clermont-Ferrand: Les Éditions Maison, 2010. 
As tropas continuaram em marcha, atravessando várias cidades da Pérsia. 0 exército passou fome e houve perdas de soldados tanto do lado romano quanto do lado persa. Em um determinado momento, ambos os corpos bélicos tiveram que fazer uma trégua para a recuperação de suas forças. Os romanos continuaram, após uma trégua de três dias, no seu caminho para Ctesifonte, alvo principal de Juliano. Os arúspices, consultados pelo Imperador durante a noite, indicaram para ele que deveria desistir de qualquer ofensiva no dia 26 junho ou adiar sua partida. Juliano, simplesmente, ignorou tal previsão. O exército retomou a estrada e, em seguida, foi surpreendido pelo inimigo por um ataque em pinças:

Quando deixamos esses territórios, assistimos os persas terem medo de nossa infantaria, devido às perdas que tiveram anteriormente. Eles nos seguiram, sem se mostrar, estruturando emboscadas contra nossas tropas. Os persas se esconderam atrás das colinas, observando nossa passagem, de forma que - legionário romano, obcecado em vigiar onde estavam os persas, não se atentou em ver que estava sendo preparada uma emboscada vinda de outras direções (AMMIEN MARCELLIN, Histoires, XXV, 3, 1).

Amiano Marcelino descreve com detalhes esse ataque e comenta a forma imprudente com a qual o Imperador reagiu. Com isso, compreendemos que o autor da Res Gestae considerou o general imprudente, porque foi para o campo de batalha sem a proteção peitoral devida (Ibid., XXV, 3, 2-5). Na sequência, os persas atingem Juliano:

\begin{abstract}
Naquele momento, Juliano, sem a devida proteção, correu de maneira imprudente para a batalha, levantando os braços e gritando para demonstrar sua fúria ao inimigo, incitando-o. Os soldados responsáveis pela proteção do Imperador esbravejavam para evitar que os demais guerreiros, dispersos pelo medo, fugissem. Mas, de repente, uma lança de cavalaria raspou o braço de Juliano e perfurou suas costelas, atravessando o lobo inferior de seu fígado. Ele tentou arrancar a lança com a mão direita, quando sentiu os músculos dos dedos cortados pela borda dupla do ferro. Tombando de seu cavalo, ele foi trazido de volta ao acampamento pelas testemunhas do drama, e recebeu atenção médica (Ibid., XXV, 3, 6-7).
\end{abstract}

Vemos abaixo o mapa que ilustra o plano de ataque do Imperador à cidade de Ctesifonte: 


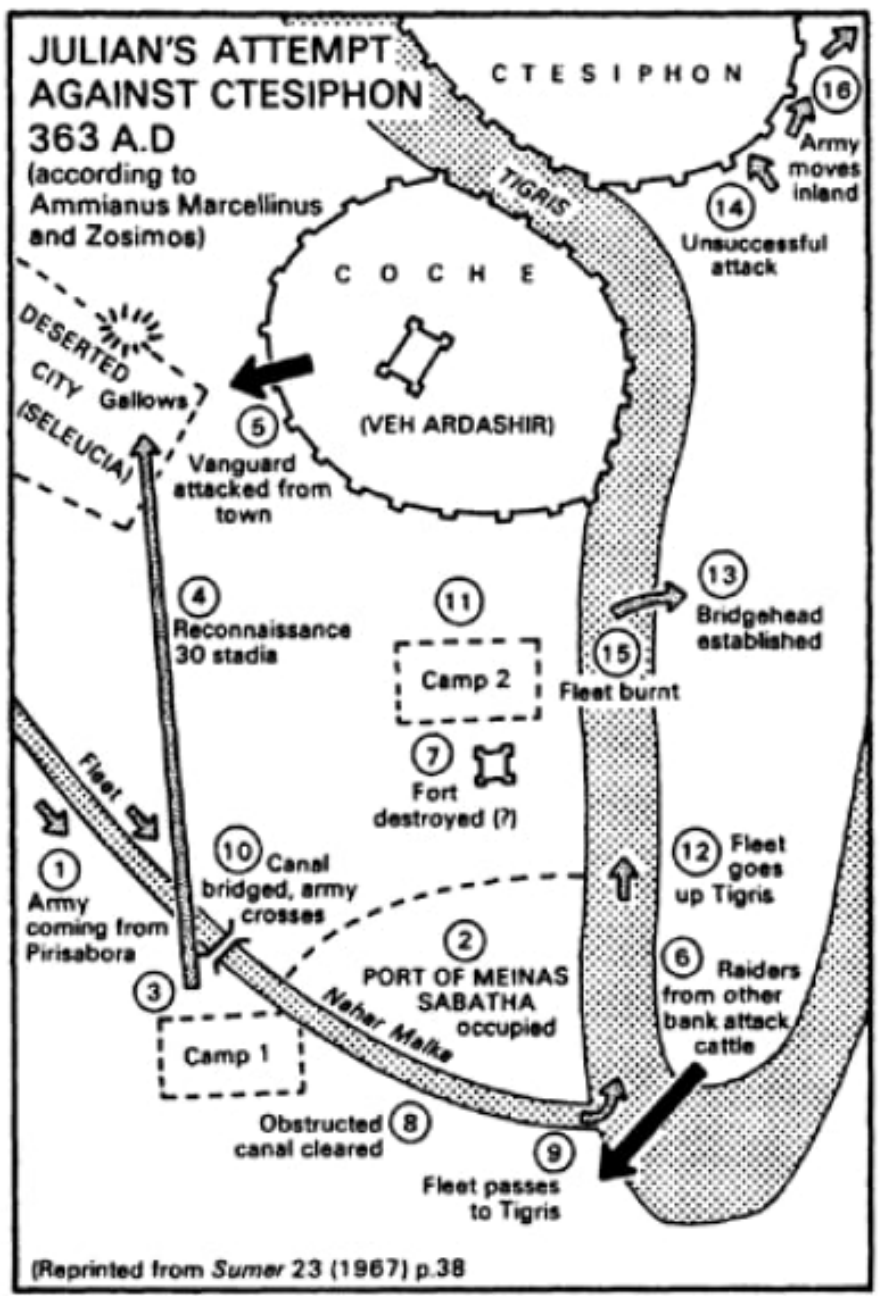

Figura 2 - $\mathrm{O}$ ataque de Juliano contra Ctesifonte

Fonte: DODGEON, MICHAEL H.; LIEU, SAMUEL N. C. The Roman Eastern frontier and the Persian wars AD 226-363. London; New York: Routledge, 1991, p. 203.

Em seu leito de morte, segundo o autor antioquiano, Juliano aceita sua partida e comenta com seus amigos que estavam presentes, Prisco de Epiro (305-395), Máximo de Éfeso (310-372) e Oribásio de Pérgamo, que não estava aflito ou triste. 0 Imperador diz que a missão que Ihe foi confiada era nunca deixar o campo de batalha 
e nem ser derrotado, não agindo como um covarde, porém morrendo com bravura (AMMIEN MARCELLIN, Histoires, XXV, 3, 15-23). Em seus últimos suspiros de vida, Juliano parecia estar conformado com a sua morte, como se já tivesse cumprido o dever que lhe foi imputado pelos deuses:

É por isso que agradeço à eterna divindade por não ter desaparecido vítima de um ataque repentino, nem acometido por uma longa e dolorosa doença, nem como os condenados, mas ter merecido deixar este mundo em plena luz, no meio de uma carreira florescente e gloriosa (Ibid., XXV, 3, 19).

Para Hengst (2010, p. 308), a narrativa de Amiano Marcelino se alterna entre os sentimentos de irritação e admiração. Por um lado, ele admira as qualidades de Juliano enquanto pessoa e general, por outro, irrita-se com a imprudência que o levou à morte, ignorando os avisos claros dos deuses. Ainda, a descrição do óbito do Imperador é modelada nos famosos exemplos de Sócrates (470-399 a.C.) e Sêneca (4 a.C.-65 d.C.). Roland Smith (1999, p. 80) disse que tal relato transforma os ferimentos fatais de Juliano em uma cena filosófica e, depois, em um obituário laudatório de um general caracterizado por um espírito heroico, atos gloriosos e majestade inata.

\section{Considerações finais}

Na obra Res Gestae, é visível que o autor tentou transmitir a face da batalha, sua sonoridade, seu impacto físico e emocional. Seus livros são repletos de sentimentos que devem ser traduzidos para a compreensão da morte do Imperador. Assim, o medo e a bravura se mesclam nas atitudes de Juliano. Acontecimentos precedentes à guerra o deixaram amargurado e alguns problemas de relacionamento com as suas tropas fizeram com que o general se sentisse frustrado, isto é, como já exposto no corpo do texto, ele foi mal compreendido no que diz respeito às suas crenças e aos seus ritos de sacrifícios. Tudo isso é demonstrado através de truques retóricos, presságios, anedotas e figuras ornamentais para convencer sua audiência e seus leitores do drama do confronto. Amiano terminou o livro XXV falando mal do tratado de paz assinado por Joviano e, depois, Juliano fez uma última aparição póstuma, como um cadáver transportado para o seu enterro em Tarso.

Ao contrário dos conselhos de seus generais, o Imperador decidiu atacar o coração da Pérsia, ou seja, a cidade de Ctesifonte. Em que pese a importância dos presságios para um neoplatônico do século IV, somos partícipes da tese de que Juliano não ignorou os presságios somente pela questão de ser um general que deveria levar as batalhas a cabo. Diante da metodologia da História das Emoções, é plausível pensarmos que o Imperador desejava ir ao encontro da morte. O primeiro autor da Antiguidade Tardia que levantou a hipótese do suicídio de Juliano foi Efraim de Nísibis (306-373), na sua obra Hinos contra Juliano. Para o autor sírio, o motivo de tal ato seria religioso. Embora ainda não tenhamos investigado a fundo a obra desse escritor, ele nos incentivou a buscar novas perspectivas sobre o tema. A soma das agrúrias passadas por Juliano em Antioquia, seu enrijecimento em relação às atitudes religiosas demonstradas em 
várias de suas cartas, assim como seu sentimento de medo diante dos presságios descritos por Marcelino, podem tê-lo levado a respeitar a vontade dos deuses de vir a óbito. Somente quando as forças de Juliano se esgotaram ele permaneceu imóvel, aceitando a morte filosoficamente como um presente dos deuses. Suas palavras finais declararam que o bem-estar dos cidadãos romanos era o seu objetivo principal. Logo, confortou seus amigos chorosos com a imagem de um neoplatonista cuja alma retornaria ao seu lar celestial.

\section{Referências}

BARNES, Timothy David. Ammianus Marcellinus and the Representation of Historical Reality. New York: Cornell University Press, 1998.

BARGAGNA, Agnese. Ammiano Lettore di Tacito persorsi di confront intertestuale, tematico e compositivo. Studi Classici e Orientali, Pisa, v. 1, p. 335-350, 2015.

BIDEZ, Joseph. La vie de l'Empereur Julien. 3a ed. Paris: Les Belles Lettres, 2012.

HENGST, Daniël den. Vir heroicis connumerandus ingeniis. Ammianus' Final Verdict on the Emperor Julian. In: BURGERSDIJK, Diederik; WAARDEN, Joop van (eds.). Emperors and Historiography. Collected Essays on the Literature of the Roman Empire. Netherlands: Brill, 2009, p. 306-320.

CARVALHO, Margarida Maria de. Relações conflituosas entre o Imperador Juliano e a cidade de Antioquia. In: CARVALHO, Margarida Maria de; FRANÇA, Susani Silveira Lemos; LOPES, Maria Aparecida de S. (orgs.). As cidades no tempo. São Paulo: Olho d’Água, 2005, p. 113-123.

CARVALHO, Margarida Maria de. Sentimentos controversos do Imperador Juliano na rota da morte: raiva, ironia e frustação (362/363 d.C.). In: CARVALHO, Margarida Maria de; OMENA, Luciane Munhoz de (orgs.). Narrativas e Materialidades sobre a Morte nas Antiguidades Oriental, Clássica e Tardia. Curitiba: CRV, 2020. [no prelo].

CARVALHO, Margarida Maria de. Uma nova discussão sobre os espaços do Imperador Juliano (361-363 d.C.). In: SILVA, Gilvan Ventura da; SILVA, Érica Cristhyane Morais da; LIMA NETO, Belchior Monteiro (orgs.). Usos do espaço no Mundo Antigo. Vitória: GM, 2018, p. 219-239.

CURRAN, John. From Jovian to Theodosius. In: CAMERON, Averil; GARNSEY, Peter (eds.). The Cambridge Ancient History. Vol. XIII. New York: Cambridge University Press, 1998.

DEVILLERS, Oliver. Fonction de l'excursus sur les Perses chez Ammien Marcellin (XXIII, 6). Vita Latina, Lyon, n. 165, p. 53-68, 2002.

FONTAINE, J. Introduction. In: AMMIEN MARCELLIN. Histoires. Livres XXIII-XXV. Texte établi et traduit par Jacques Fontaine. 3 ed. Paris: Les Belles Lettres, t. 4, p. 1, 2002 , p. 7-74. 
GRATTAROLA, Pio. Ammiano Marcellino fra la « reazione » pagana e il cristianesimo. Aevum, Milano, a. 55, f. 1, p. 80-95, gennaio-aprile. 1981.

RAMOS, Paméla. La veritable Histoire de Julien. Paris: Les Belles Lettres, 2012.

ROHRBACHER, David. Ammianus' Roman Digressions and the Audience of the Res Gestae. In: MARINCOLA, John (ed.). A Companion to Greek and Roman Historiography. New Jersey: John Wiley \& Sons, 2007, p. 447-452.

ROLFE, John Carow. Introduction. In: AMMIANUS MARCELLINUS. History. Books 14-19. With an English translation by John C. Rolfe. Cambridge: University Press, v. 1, 1950.

ROSENWEIN, Barbara H. História das Emoções. Problemas e métodos. São Paulo: Letra e Voz, 2011.

SEAGER, Robin. Perceptions of Eastern Frontier Policy in Ammianus, Libanius, and Julian (337-363). The Classical Quarterly, New York, vol. 47, n. 1, p. 253-268, 1997.

SIDWELL, Barbara. Ammianus Marcellinus and the anger of Julian. Journal of the Classical Association of Victoria, Melbourne, v. 21, p. 56-75, 2008.

SMITH, Roland. Telling tales: Ammianus' narrative of the Persian expedition of Julian. In: DRIJVERS, Jan Willem; HUNT, David (eds.). The Late Roman World and its Historians. Interpreting Ammianus Marcellinus. London: Routledge, 1999, p. 79-92.

THOMPSON, Edward Arthur. The historical work of Ammianus Marcellinus. London: Cambridge University Press, 1947.

WILSHIRE, Leland Edward. Did Ammianus Marcellinus Write a Continuation of Tacitus. The Classical Journal, Northfield, v. 68, n. 3, p. 221-227, Feb. - Mar. 1973.

\section{Fontes}

AMMIANUS MARCELLINUS. History. Books 20-26. With an English translation by John C. Rolfe. Cambridge: University Press, v. 2, 1940.

AMMIEN MARCELLIN. Histoires. Livres XXIII-XXV. Texte établi et traduit par Jacques Fontaine. 3a ed. Paris: Les Belles Lettres, t. 4, p. 1, 2002.

EPHREM THE SYRIAN. Hymns against Julian. Introduction and notes by Samuel N. C. Lieu. Translation by Judith M. Lieu. In: LIEU, Samuel N. C. The Emperor Julian Panegyric and Polemic. 2 ed. Liverpool: University Press, 1989.

ORIBASE. Collection Médicale. A Julien. Avec une introduction, des notes, des tables et des planches par les docteurs U. C. Bussemaker et Charles Daremberg. Paris: Imprimerie Nationale, 1851.

EUNAPIUS. The lives of the Sophists. With an English translation by Wilmer Cave Wright. London: The Loeb Classical Library, 1921. 
THEODOSIANI. Libri XIII: cvm constitvtionibvs sirmondianis leges novellae ad theodosianvm pertinentes. Edidervnt Th. Mommsen et Pavlvs M. Meyer. Zurich: Weidmannos, 1970-1971. 4v.

\section{Notas}

1 Todas as datas utilizadas neste artigo se referem ao período depois de Cristo.

2 Assunto que foi desenvolvido em meu último capítulo de livro a ser publicado (CARVALHO, 2020, no prelo).

${ }^{3}$ Centro administrativo do Império Persa.

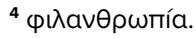

5 Tema desenvolvido em (CARVALHO, 2005).

6 Sofista e professor da Escola de Atenas.

Margarida Maria de CARVALHO. Professora Doutora em História Econômica/História Antiga Assistente MS-3 do Departamento de História e do Programa de Pós-graduação em História da Universidade Estadual Paulista "Júlio de Mesquita Filho" - Faculdade de Ciências Humanas e Sociais, campus de Franca. Av. Eufrásio Monteiro Petráglia, 900. CEP: 14409-160 - Franca, SP - Brasil. Bolsista de Produtividade em Pesquisa do CNPq - Nível 2. Pesquisadora da FAPESP - Processo: 2018/03323-9. 